\title{
Urban residential environments and senior citizens' longevity in megacity areas: the importance of walkable green spaces
}

\author{
T Takano, K Nakamura, M Watanabe
}

See end of article for authors' affiliations

.....................

Correspondence to: Professor T Takano, Health Promotion/International

Health, Division of Public

Health, Graduate School of

Tokyo Medical and Dental

University, Yushima

1-5-45, Bunkyo-ku, Tokyo

113-8519, Japan;

takano.hlth@tmd.ac.jp

Accepted for publication 15 May 2002

Study objectives: To study the association between greenery filled public areas that are nearby a residence and easy to walk in and the longevity of senior citizens in a densely populated, developed megacity.

Design: Cohort study.

Methods: The authors analysed the five year survival of 3144 people born in 1903, 1908, 1913, or 1918 who consented to a follow up survey from the records of registered Tokyo citizens in relation to baseline residential environment characteristics in 1992.

Main results: The survival of 2211 and the death of 897 (98.9\% follow up) were confirmed. The probability of five year survival of the senior citizens studied increased in accordance with the space for taking a stroll near the residence $(p<0.01)$, parks and tree lined streets near the residence $(p<0.05)$, and their preference to continue to live in their current community $(p<0.01)$. The principal component analysis from the baseline residential environment characteristics identified two environment related factors: the factor of walkable green streets and spaces near the residence and the factor of a positive attitude to a person's own community. After controlling the effects of the residents' age, sex, marital status, and socioeconomic status, the factor of walkable green streets and spaces near the residence showed significant predictive value for the survival of the urban senior citizens over the following five years $(p<0.01)$.

Conclusions: Living in areas with walkable green spaces positively influenced the longevity of urban senior citizens independent of their age, sex, marital status, baseline functional status, and socioeconomic status. Greenery filled public areas that are nearby and easy to walk in should be further emphasised in urban planning for the development and re-development of densely populated areas in a megacity. Close collaboration should be undertaken among the health, construction, civil engineering, planning, and other concerned sectors in the context of the healthy urban policy, so as to promote the health of senior citizens.

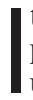

$\mathrm{t}$ is generally recognised that greenery filled public areas provide comfortable and pleasant living environments for urban residents. ${ }^{12}$ Comfortableness, feeling comfortable, in relation to physical environments in densely populated areas has been studied by measuring people's preferences. ${ }^{3}$ However, there is a controversy as to whether substantial positive health outcomes result from living in localities with greenery filled public areas. ${ }^{4}$ Hence, the tendency has been to regard the provision of greenery filled public areas merely as a matter of preference.

For convenience, this paper will refer to greenery filled public areas that are nearby and easy to walk in such as parks and tree lined streets as "walkable green spaces".

The health influences of residential environments have not been investigated adequately. ${ }^{5}$ It generally has been acknowledged that it is difficult to demonstrate an association between health outcomes and residential environments because the health consequences often are not apparent until some years have passed, and because many other health determinants also affect both the environmental conditions of residential areas and the health status of residents. However, there is a growing concern for physical environmental factors in facilitating or modifying different health behaviours conducive to health. ${ }^{6}$ Thus, we conducted a longitudinal cohort study to obtain evidence showing the health consequences of living in a residence that has walkable green spaces nearby.

It has been reported that in an urban society a wide variety of physical, social, and economic factors exhibit interrelation- ships while also affecting the health of residents. ${ }^{7-10}$ Therefore, in this cohort study, we considered multiple variables concerning physical, social, and economic environments, and we analysed independent effect of walkable green spaces on the longevity of senior citizens.

Health promotion of older people in a megacity has become a prime concern in an aging society. ${ }^{11-13}$ It is well known that a sedentary lifestyle is a key risk of premature morbidity and mortality. ${ }^{14}$ For older adults, a sedentary lifestyle is a greater risk of reducing their physical function than that for younger adults. ${ }^{15}$ Therefore, to facilitate healthy aging, physically active living should be encouraged by deliberate arrangements. Giving an exercise prescription was reported as an effective intervention for sedentary patients to facilitate their physically active living. ${ }^{16}{ }^{17}$ To approach a healthy population in general before they become sedentary patients, we considered there are some appropriate physical environment conditions conducive to their physically active living and longevity. We were particularly interested to study whether walkable green spaces provide a supportive environment that promotes the health of senior citizens in densely populated urban areas.

Collaboration of the health and urban planning sectors would be more firmly grounded if there were evidence of the health promoting outcomes of particular environments that can be realised through urban planning. People's preferences regarding a comfortable living environment are subjective and often are based on intangible factors. In contrast, longevity is an objective measure that can be directly quantified. Health 
issues can provide strong, logical factors to be considered in urban planning decision making. Demonstrable evidence that living in an area that has walkable green spaces has a positive impact on longevity would constitute key evidence for policy making and could facilitate intersectoral collaboration regarding health promoting urban planning.

Thus, the objective of this study was to investigate, through a cohort study of older people, the association between walkable green spaces near the residence and the longevity of senior citizens in a densely populated, developed megacity in order to provide facts for evidence based policy making and to advance intersectoral collaboration in urban planning so as to promote the health of senior citizens.

\section{METHODS \\ Sampling}

A representative sample of residents born in 1903, 1908, 1913, or 1918 was selected from resident registration records in two cities in the Tokyo metropolitan area-one in the east part and the other in the west part-in 1989. The following sampling rates were applied: $1 / 2$ for people born in 1913 or 1918 , and $1 / 1$ for people born in 1903 or 1908. A total of 7362 people were selected and asked to participate in a mail follow up survey of their individual functional status and health. A total of 5924 people consented for this mail questionnaire follow up survey. In 1992, a subsequent questionnaire survey was conducted of those who agreed to participate. We asked about their residence's environmental conditions, and about their functional status, lifestyles, living arrangements, and socioeconomic status. A total of 3144 people responded to the survey by consenting to use their data with their resident registry records in later years. This population was defined as the 1992 cohort population to be followed up in 1997.

\section{Baseline assessment}

A baseline assessment of the 1992 cohort, which consisted of 1339 men and 1805 women, was completed during April to June 1992. At the 1992 survey, nine items relating to residential environment were asked and all the responses were recorded. Percentage of responders to the individual questionnaire items were from $94.2 \%$ to $96.9 \%$. The questionnaire were: space near the residence for taking a stroll, a park, and tree lined streets near the residence, noise from automobiles and factories near the residence, the level of crime in the community, hours of sunlight at the residence, existence of a garden at the residence, whether the residence faced a road with a regular bus service, active communication among neighbouring residents, and preference to continue to live in the current community. The amount of monthly living expenses was asked and its answer was used as an indicator of the socioeconomic status of participants. Marital status was asked and its answer was used as an indicator of participants' living arrangements.

\section{Follow up}

Survival of the respondents as of 31 May 1997 were followed up by our obtaining official residence records from their local governments, based on each participant's informed consent thereto.

\section{Analysis}

The association between baseline residential-environment characteristics and the five year survival of the subject senior citizens was analysed by use of the $\chi^{2}$, and Kruskal-Wallis tests.

Principal component analysis with Varimax rotation was performed to extract residential-environmental factors from the variables of environmental characteristics that showed significant univariate statistical associations with the five year survival of male and/or female subjects, as calculated in the earlier tests.
Associations between each of the baseline residentialenvironmental factors and five year survival were examined by multiple logistic regression analysis. Independent influences of residential-environment conditions, represented by factor scores obtained by the earlier analysis, were calculated after excluding the effects of age, sex, marital status, and socioeconomic status. To exclude the effects of lower functional status at the baseline in individual regression models, we examined logistic regression coefficients for the subjects of any levels of functional status, and those for subjects who did not need help to get out of bed at the baseline time.

\section{RESULTS}

The survival of 2211 and the death of 897 of the 3144 persons in the 1992 cohort population were confirmed five years later, in 1997 . The follow up rate was $98.9 \%$. The five year survival percentage was higher among women $(75.2 \%)$ than among men $(65.9 \%)$. The five year survival percentage decreased as the baseline age of the subjects increased, being $85.7 \%$ among those 73 years of age in the baseline year and $43.7 \%$ among those 88 years of age in the baseline year.

Table 1 shows five year survival percentages of older people in relation to the characteristics of their residential environment, sex, and age. For the male and female subjects in total, the five year survival percentages were greater for subjects having either a space near their residence for taking strolls $(p<0.01)$, or parks and tree lined streets near their residence $(p<0.05)$. These results were observed for each of the age categories. The five year survival percentage of senior citizens was greater among those who preferred to continue to live in their current community than among those who did not express such a preference $(\mathrm{p}<0.01)$; this was observed for each of the age categories. The five year survival percentage of senior citizens increased in accordance with the number of hours of sunlight at their residence $(\mathrm{p}<0.01)$; this was also observed for the age categories of 73 and 78 in the baseline year.

Statistically greater survival rates were observed among male subjects who were not subject to noise from automobiles and factories near their residence $(p<0.01)$ or who enjoyed sunlight at their residence $(p<0.05)$, but such statistically greater survival rates were not observed among female subjects under the same conditions.

Among female subjects, five year survival percentages were greater for those who claimed to have active communication with their neighbours $(\mathrm{p}<0.05)$ and among those who preferred to continue to live in their current community $(\mathrm{p}<0.01)$, but such greater survival percentages were not observed among comparable male subjects.

Table 2 shows the factor loading of the obtained two factors from the principal component analysis with Varimax rotation of six living environment variables. The obtained two factors explained $50.0 \%$ of the variances of the six variables entered. The first factor represented "walkable green streets and spaces near the residence," and the other represented "a positive attitude towards one's own community." The average of the standardised factor score of "walkable green streets and spaces near the residence" among men $(-0.0471)$ was lower than that among women $(0.0375)(\mathrm{p}<0.05)$. The average of the standardised factor score of "a positive attitude to one's own community" among men $(-0.0707)$ was lower than that among women $(0.0562)(\mathrm{p}<0.01)$.

Table 3 summarises the results of multiple logistic regression analysis. It presents odds ratios with 95\% confidence intervals and their significance level for the residential-environment factor of walkable green streets and spaces, in order to predict the five year survival of older people. It shows the odds ratios after adjustment for factor score of another residential-environment factor, age, sex, marital 


\begin{tabular}{|c|c|c|c|c|c|c|c|c|c|c|c|c|c|c|}
\hline \multirow[b]{4}{*}{ Age at baseline } & \multirow[b]{4}{*}{$(\mathrm{n})$} & \multirow{3}{*}{$\begin{array}{l}\text { Female/male } \\
\text { Five year } \\
\text { survival } \\
\text { percentage }\end{array}$} & \multirow{4}{*}{$\chi^{2}$ test } & \multirow{4}{*}{$\mathrm{K}-\mathrm{W}$ test } & \multirow{3}{*}{$\begin{array}{l}\text { Female } \\
\text { Five year } \\
\text { survival } \\
\text { percentage }\end{array}$} & \multirow{4}{*}{$\chi^{2}$ test } & \multirow{4}{*}{$\mathrm{K}-\mathrm{W}$ test } & \multirow{3}{*}{$\begin{array}{l}\text { Male } \\
\text { Five year } \\
\text { survival } \\
\text { percentage }\end{array}$} & \multirow{4}{*}{$\chi^{2}$ test } & \multirow{4}{*}{ K-W test } & \multicolumn{4}{|c|}{ Female/male by age } \\
\hline & & & & & & & & & & & 73 & 78 & 83 & 88 \\
\hline & & & & & & & & & & & \multicolumn{4}{|c|}{ Five year survival percentage } \\
\hline & & 3001 & & & 1689 & & & 1312 & & & 1075 & 842 & 864 & 327 \\
\hline All & (3001) & 71.1 & & & 75.2 & & & 65.9 & & & 85.7 & 75.9 & 58.7 & 43.7 \\
\hline \multicolumn{15}{|c|}{ Space for taking a stroll near the residence } \\
\hline Enough space available & (1425) & 73.8 & \multirow{4}{*}{ ** } & \multirow{4}{*}{ ** } & 76.5 & & & 70.5 & & & 86.5 & 80.7 & 60.9 & 43.8 \\
\hline Some space available, not enough & (1314) & 70.1 & & & 75.7 & * & & 62.5 & & & 85.7 & 71.6 & 58.2 & 45.3 \\
\hline Very little space available & (249) & 67.9 & & & 72.3 & * & *NS & 61.4 & ** & ** & 84.5 & 72.3 & 60.3 & 42.9 \\
\hline None & (79) & 55.7 & & & 59.6 & & & 48.1 & & & 73.3 & 85.7 & 33.3 & 18.2 \\
\hline Parks and tree lined streets near the re & & & & & & & & & & & & & & \\
\hline Plenty & (915) & 74.2 & & & 77.3 & & & 70.4 & & & 87.1 & 82.5 & 62.1 & 43.4 \\
\hline Some & (1328) & 70.0 & * & * & 74.9 & & & 63.7 & * & & 83.5 & 71.8 & 58.6 & 45.7 \\
\hline Little & $(583)$ & 70.8 & * & * & 74.0 & NS & NS & 66.4 & * & NS & 88.2 & 75.5 & 56.8 & 36.8 \\
\hline Very little & (231) & 66.2 & & & 69.8 & & & 60.9 & & & 84.8 & 75.4 & 54.7 & 39.4 \\
\hline Noise from automobiles and factories & & & & & & & & & & & & & & \\
\hline Have no trouble & (882) & 73.7 & & & 74.2 & & & 73.1 & & & 88.6 & 81.0 & 62.7 & 43.8 \\
\hline Seldom have troubles & (1127) & 70.4 & & & 75.2 & & & 64.2 & $* *$ & $* *$ & 83.6 & 75.6 & 58.0 & 47.8 \\
\hline Sometimes have troubles & $(780)$ & 69.6 & NS & NS & 75.6 & NS & NS & 61.9 & *** & $\star \star *$ & 84.3 & 70.6 & 56.9 & 37.1 \\
\hline Usually have troubles & (247) & 71.3 & & & 76.4 & & & 63.6 & & & 91.1 & 72.2 & 55.0 & 36.0 \\
\hline Safetiness against crimes in the comm & & & & & & & & & & & & & & \\
\hline Perceived as very safe & (701) & 71.8 & & & 75.5 & & & 67.2 & & & 87.3 & 80.3 & 59.7 & 46.1 \\
\hline Perceived as relatively safe & (2159) & 71.3 & & & 75.4 & & & 66.0 & & & 84.5 & 74.9 & 59.7 & 43.1 \\
\hline Perceived as relatively unsafe & (183) & 68.3 & NS & NS & 69.4 & NS & NS & 66.1 & NS & NS & 94.1 & 71.1 & 45.6 & 40.0 \\
\hline Perceived as unsafe & (11) & 72.7 & & & 87.5 & & & 33.3 & & & 100.0 & 100.0 & 50.0 & - \\
\hline Hours of sunlight at the residence (Apr & & & & & & & & & & & & & & \\
\hline 5 hours and longer / day & (1703) & 72.5 & & & 76.5 & & & 67.8 & & & 87.9 & 77.0 & 59.3 & 38.5 \\
\hline $3-5$ hours / day & $(760)$ & 70.8 & & * & 75.5 & & & 64.4 & * & & 83.6 & 76.7 & 59.0 & 52.4 \\
\hline 1-3 hours / day & (432) & 70.4 & 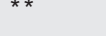 & * & 73.3 & NS & NS & 65.4 & * & * & 80.4 & 71.5 & 63.4 & 50.0 \\
\hline Less than 1 hour / day & (153) & 59.5 & & & 65.3 & & & 48.1 & & & 81.4 & 73.5 & 43.1 & 33.3 \\
\hline Garden at the residence & & & & & & & & & & & & & & \\
\hline Have garden 2 units and larger & (1785) & 71.3 & & & 74.4 & & & 67.6 & & & 85.9 & 78.2 & 60.4 & 43.4 \\
\hline Have garden less than 2 units & (349) & 71.1 & NS & NS & 77.8 & NS & NS & 62.3 & NS & NS & 83.6 & 73.2 & 61.1 & 41.4 \\
\hline None & (867) & 70.9 & & & 75.6 & & & 63.6 & & & 86.3 & 72.3 & 54.3 & 46.0 \\
\hline Residence facing a road with a regula & & & & & & & & & & & & & & \\
\hline No & (2251) & 71.3 & NS & NS & 74.5 & NS & NS & 67.0 & NS & NS & 85.5 & 77.8 & 58.3 & 43.2 \\
\hline Yes & (782) & 71.5 & NS & NS & 77.0 & NS & NS & 64.3 & NS & NS & 85.9 & 72.0 & 61.3 & 44.2 \\
\hline Active communication among neighbo & & & & & & & & & & & & & & \\
\hline Very good & (857) & 71.5 & & & 75.6 & & & 66.3 & & NS & 86.6 & 77.6 & 58.6 & 37.5 \\
\hline Relatively good & $(1366)$ & 73.1 & & & 78.6 & & * & 66.3 & & NS & 85.9 & 77.4 & 61.6 & 46.4 \\
\hline Not so good & $(836)$ & 60.0 & NS & NS & 70.2 & ** & * & 64.3 & NS & NS & 83.9 & 72.2 & 56.0 & 40.0 \\
\hline Almost none & (122) & 70.5 & & & 69.3 & & & 72.1 & & NS & 91.2 & 75.8 & 51.4 & 61.1 \\
\hline Preference to continue to live in the cu & & & & & & & & & & & & & & \\
\hline Would like to continue to live & (2599) & 72.2 & & & 76.6 & & & 66.7 & & & 86.3 & 76.4 & 60.4 & 46.2 \\
\hline Would not like to continue to live & $(104)$ & 69.2 & ** & - & 69.1 & ** & - & 69.4 & NS & - & 83.3 & 75.0 & 58.3 & 25.0 \\
\hline Not know & (330) & 65.5 & & & 67.4 & & & 61.7 & & & 84.5 & 72.7 & 50.0 & 20.0 \\
\hline
\end{tabular}


Table 2 Factor loading for selected living environmental factors

\begin{tabular}{lll}
\hline & Factor 1 & Factor 2 \\
\hline Space for easy street walk around the residence & 0.822 & 0.040 \\
Parks and green lined streets around residence & 0.822 & 0.034 \\
Less noise from automobiles and factories near the residence & 0.553 & 0.117 \\
Longer hours of sunlight at the residence & 0.360 & 0.261 \\
Active communication among neighbouring residents & 0.006 & 0.798 \\
Preference to continue to live in the current community & 0.158 & 0.686 \\
$r^{2}$ & 0.326 & 0.174 \\
\hline Results of the factor analysis with Varimax rotation by the selected living environmental factors. Factor 1 was \\
considered to represent "walkable green streets and spaces near the residence". Factor 2 was considered to \\
represent "positive attitude to one's own community".
\end{tabular}

Table 3 Influence of residential environment factor of walkable green spaces near the residence on five year survival of older people

\begin{tabular}{|c|c|c|}
\hline \multirow[b]{2}{*}{ Subjects entered in the logistic model } & \multicolumn{2}{|c|}{ Walkable green spaces } \\
\hline & Odds ratio & $95 \%$ confidence intervals \\
\hline \multicolumn{3}{|l|}{ All participated in the follow up } \\
\hline \multicolumn{3}{|l|}{ Independent variables in each model } \\
\hline Residential environmental factors & 1.15 & 1.06 to $1.25^{* * *}$ \\
\hline Residential environmental factors, age, and sex & 1.16 & 1.07 to $1.27 * * *$ \\
\hline Residential environmental factors, age, sex, and living arrangement & 1.16 & 1.07 to $1.27 * * *$ \\
\hline Residential environmental factors, age, sex, living arrangement, and living expenses & 1.13 & 1.03 to $1.24 * *$ \\
\hline \multicolumn{3}{|l|}{$\begin{array}{l}\text { Subjects who did not need help to get out of bed at baseline } \\
\text { Independent variables in each model }\end{array}$} \\
\hline Residential environmental factors & 1.16 & 1.07 to $1.26 * * *$ \\
\hline Residential environmental factors, age, and sex & 1.17 & 1.07 to $1.28 * * *$ \\
\hline Residential environmental factors, age, sex, and living arrangement & 1.17 & 1.07 to $1.28 * * *$ \\
\hline Residential environmental factors, age, sex, living arrangement, and living expenses & 1.14 & 1.03 to $1.25^{*}$ \\
\hline \multicolumn{3}{|c|}{$\begin{array}{l}{ }^{*} \mathrm{p}<0.05 ;{ }^{*} \mathrm{p}<0.01 ;{ }^{* *} \mathrm{p}<0.001 \text {. Dependent variable (survival }=1 \text {; deceased }=0 \text { ). Independent variables were coded as follows: residential } \\
\text { environment factors were (walkable green spaces) and (positive attitude to one's own community) (factor scores obtained by the factor analysis); age (five } \\
\text { year intervals as one unit); sex (female }=1 \text {; male =0); marital status (living with spouse =1; others =0); living expenses ( } 7 \text { gradient score according to the } \\
\text { amount of monthly living expenses). }\end{array}$} \\
\hline
\end{tabular}

status, and living expenses for all of the people who were followed up and for people who did not need help to get out of bed at baseline. A calculation involving only the male subjects showed that the factor of walkable green streets and spaces near the residence was a significant predictor of survival in five years $(\mathrm{p}<0.05)$, after excluding the effects of age, marital status, attitude towards one's own community, and living expenses.

The following five living environment variables were found to have a significantly independently impact on five year survival of older people: younger age, being a female in sex, living with one's spouse, higher living expenses, and positive attitude towards one's own community individually independently significantly contributed to predicting the five year survival of older people. These associations were found in the both models with and without subjects who did not need help to get out of bed at the baseline time.

\section{DISCUSSION}

The quality of the physical environments near a residenceobserved as the space for taking a stroll, tree lined streets, the number of hours of sunlight at the residence, and less noise from automobiles and factories-showed a positive association with the longevity of senior citizens. The factor of walkable green streets and spaces near the residence significantly and positively influenced the five year survival of senior citizens independent of a person's age, sex, marital status, attitude toward their own community, and socioeconomic status. This association between walkable green spaces and longevity remained after excluding subjects of very low baseline functional status. These results clearly show that living in an area with walkable green spaces positively influenced on the longevity of senior citizens.

Five year survival of the subjects was confirmed by examining resident registration records, which are one of the reliable sources of official information regarding the life and death of people in Japan. ${ }^{18}$ The follow up percentage of $98.9 \%$ after the five year period was considered high enough to reflect the entire population. It is considered that the average five year survival percentage of the baseline group, $71.1 \%$, as compared with the follow up percentage, was an appropriate proportion for conducting statistical analysis throughout this study.

It is probable that the availability of space for taking a stroll positively contributed to longevity. Booth et a $l^{19}$ demonstrated that the availability of space for walking increased the amount of a senior citizen's activity. It has also been reported that more active older people gain a higher functional status and live longer. ${ }^{20}$ In addition, the positive influence of walking to reduce risk for coronary heart disease among women was recently indicated. ${ }^{21}$ The availability of space near your own residence for taking a stroll is believed to increase the chances of walking outside of the residence, which helps to maintain a high physical functional status.

The results with the factor of walkable green streets and spaces that are independent of personal characteristics suggested that the value of parks and tree lined streets near residences is particularly high in densely populated urban areas for the senior citizens living there. Tanaka et al ${ }^{22}$ have demonstrated, by using aggregated data, a positive correlation between woodland/farmland area and lower mortality rates for residents of cities having a density of more than 4000 inhabitants per $\mathrm{km}^{2}$, but not among cities having a sparse population density. An apparent association between senior 
citizens' longevity and walkable green spaces near their residence, which was observed in the present cohort study, was consistent with our previous ecological study. The present cohort study was carried out in highly densely populated urban areas; the average population density of our study areas was 13050 inhabitants per $\mathrm{km}^{2}$. The per capita park space in Tokyo was $5.18 \mathrm{~m}^{2}$ in 1997, and the "greenery rate" as a percentage of the sum of the areas of forests, grass area, agricultural land, garden greens, parks, trees along streets, riverside and pondside space was $29 \%$ in the centre area of Tokyo. ${ }^{23}$ If you consider that most of the Tokyo metropolitan area is a highly densely populated urban area, the results obtained in this study can be regarded as important evidence on which urban planning in Tokyo should be based.

Urbanisation has accelerated the spread of rapid motorisation and the development of road networks in densely populated urban areas. ${ }^{24}$ Congested traffic on narrow roads, highly concentrated development, and little open space for relaxing places are some examples of characteristics about which we are concerned..$^{25}$ Although all of the measurements of atmospheric sulphur oxides, $85.2 \%$ of measurements of atmospheric nitrogen oxides, and $78.6 \%$ of measurements of suspended particulate matter from general monitoring stations have met the environmental standard in the urban centre of Tokyo, ${ }^{27}$ the long term influence of slightly unpreferable air quality on senior citizens is a matter of concern. ${ }^{28}$ In such a congested environment, existence of greenery along the streets and small parks within residential zones is considered to improve air quality and provide favourable conditions for the living of senior citizens. ${ }^{23}$ A number of studies have shown that active living helps to maintain and improve the functional status of older people. ${ }^{29-31}$ The current situations in urban environments might discourage the elderly from moving around easily outside of their residence. It is generally acknowledged that green spaces provide settings for healthy exercise and that they induce citizens to walk. ${ }^{32}$ It was reported that community groups are walking along newly developed walking trails with greenery by a river in the study area. $^{33}$ It was considered that living in an area that provides good access to walkable green spaces facilitates activities outside a person's residence. Studies have shown that walkable green spaces in residential areas contribute to the health of senior citizens, in part by facilitating their activity outside of their residence.

It has been pointed out that the ability to live in a better residential environment is associated with higher socioeconomic status. ${ }^{34}$ It is also known that there is an association between higher income and a lower risk of mortality. ${ }^{35}{ }^{36}$ This study showed a significant association between socioeconomic status and longevity. However, it is noteworthy that we found a clear and significant association between walkable green spaces and longevity, even after excluding the influence of socioeconomic conditions on longevity. Furthermore, after excluding the influence of a person's baseline functional status, there still was a significant association between walkable green spaces and longevity.

Our findings suggested that if favourably walkable green streets and spaces were provided, the health of senior citizens would be promoted further, regardless of their socioeconomic status. These results could be generalised in a densely populated urban centre where senior citizens live in medium rise to high rise apartment housing complexes without their own gardens or in detached houses with limited areas for your own garden. The obtained evidence that walkable green streets and spaces promote the health of senior citizens was considered to be useful in supporting a decisive shift in the longstanding urban planning policy debate in favour of the proponents of public policies that put priority on health. This evidence also strongly supports the preference of people for comfortable living environments. Vision sharing and consensus building in the community for city planning would be

\section{Key points}

- A five year cohort study showed that residential environments with walkable green spaces positively influenced the longevity of urban senior citizens.

- This association was observed independent of a person's age, sex, marital status, baseline functional status, and socioeconomic status.

- The obtained evidence is believed to constitute a basis for a decisive shift in favour of urban planning policy that promotes the health of residents.

- The provision of greenery filled public areas that are nearby and easy to walk in should be advanced by intersectoral collaboration.

more constructive if supported not only by intangible preferences but also by substantial evidence showing health outcomes.

Master plans for urban development should pay more attention to maintaining and increasing greenery filled public areas that are easy to walk in and are within easy walking distance of every household. Closer and more effective collaboration among health, construction, civil engineering, planning, and other relevant sectors including government agencies, which has been minimal until now, should be encouraged more, on the basis of the present evidence.

In conclusion, based on a five year follow up cohort study of 3144 older people in Tokyo, a densely populated megacity, the longevity of senior citizens is positively influenced by their living in areas with walkable green spaces, independent of a person's age, sex, marital status, baseline functional status, and socioeconomic status. Greenery filled public areas that are near to residences and easy to walk in should be further emphasised in the development and redevelopment of densely populated areas in a megacity through intersectoral collaboration.

..........................

Authors' affiliations

T Takano, K Nakamura, M Watanabe, Health Promotion/International Health, Division of Public Health, Graduate School of Tokyo Medical and Dental University, Tokyo, Japan

Funding: this work has been supported by a grant in aid for scientific research by the Ministry of Education, Japan.

Conflicts of interest: none.

\section{REFERENCES}

1 Lawrence RJ. Wanted: designs for health in the urban environment. World Health Forum 1996:17:363-6.

2 Bureau of City Planning, Tokyo Metropolitan Government. Green master plan of Tokyo. Tokyo: Tokyo Metropolitan Government, 2000.

3 Harashina S, Nakaguchi T. Consideration on residential environmental indicators systems-introducing accessibility concept. Environment and Information Science 1990;19:130-9.

4 Ohnishi T. Urban renovation and its challenges. Urban Problems 1997;88:3-13

5 Stuck AE, Walthert JM, Nikolaus T, et al. Risk factors for functional status decline in community-living elderly people: a systematic literature review. Soc Sci Med 1999:48:445-69.

6 Owen N, Leslie E, Salmon J, et al. Environmental determinants of physical activity and sedentary behavior. Exercise and Sport Sciences Reviews 2000;28:153-8.

7 Haan M. Kaplan GA. Camacho T. Poverty and health. Prospective evidence from the Alameda County Study. Am J Epidemiol 1987; 125:989-98.

8 Ecob R, Jones K. Mortality variations in England and Wales between types of place: an analysis of the ONS longitudinal study. Soc Sci Med 1998:47:2055-66.

9 Breeze E, Sloggett A, Fletcher A. Socioeconomic and demographic predictors of mortality and institutional residence among middle aged and older people: results from the Longitudinal Study. J Epidemiol Community Health 1999;53:765-74.

10 Takano T, Nakamura K. An analysis of health levels and various indicators of urban environments for Healthy Cities projects. J Epidemiol Community Health 2001;55:263-70. 
11 Kalache A, Keller I. The graying world: a challenge for the twenty-first century. Science Progress 2000;83:33-54

12 Patterson C, Feightner J. Promoting the health of senior citizens. Can Med Assoc J 1997; 157: 1 107-13.

13 Policy and Planning Section, Tokyo Metropolitan Government. Tokyo Plan 2000. Tokyo: Tokyo Metropolitan Government, 2000.

14 Blair SN, Kohl HW, Paffenbarger RS, et al. Physical fitness and all cause mortality. A prospective study of healthy men and women. JAMA 1989;262:2395-401

15 McGuire DK, Levine BD, Williamson JW, et al. A 30-year follow-up of the Dallas Bedrest and Training Study: II. Effect of age on cardiovascular adaptation to exercise training. Circulation 2001;104:1358-66.

16 Swinburn BA, Walter LG, Arroll B, et al. Green prescriptions: attitudes and perceptions of general practitioners towards prescribing exercise. $\mathrm{Br}$ J Gen Pract 1997:47:567-9.

17 Swinburn BA, Walter LG, Arroll B, et al. The green prescription study: a randomized controlled trial of written exercise advice provided by general practitioners. Am J Public Health 1998;88:288-91.

18 Shichoson Jichi Kenkyukai. Outline of the population by resident records. Tokyo: Kokudo Chiri Kyokai, 2000.

19 Booth ML, Owen N, Bauman A, et al. Social-cognitive and perceived environment influences associated with physical activity in older Australians. Prev Med 2000;31:15-22.

20 Guralnik JM, Seeman TE, Tinetti ME, et al. Validation and use of performance measures of functioning in a non-disabled older population: MacArthur studies of successful aging. Aging 1994;6:410-19.

21 Lee IM, Rexrode KM, Cook NR, et al. Physical activity and coronary heart disease in women. JAMA 2001;285:1447-54.

22 Tanaka A, Takano T, Nakamura K, et al. Health levels influence by urban residential conditions in a megacity - Tokyo. Urban Studies 1996;33:879-94.

23 Bureau of City Planning, Tokyo Metropolitan Government. Tokyo green plan. Tokyo: Tokyo Metropolitan Government, 2001

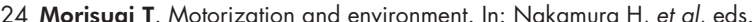
City and environment. Tokyo: Gyosei, 1992:81-7.

25 Teo P. Space to grown old in: the availability of public spaces for elderly persons in Singapore. Urban Studies 1997;34:419-39.

26 Gouveia N, Fletcher T. Time series analysis of air pollution and mortality: effects by cause, age and socioeconomic status. J Epidemiol Community Health 2000:54:750-5.

27 Bureau of Environment, Tokyo Metropolitan Government. The environment in Tokyo. Tokyo: Tokyo Metropolitan Government, 2001.

28 Burnett R, Ma R, Jerrett M, et al. The spatial association between community air pollution and mortality: a new method of analyzing correlated geographic cohort data. Environ Health Perspect $2001 ; 109: 375-80$

29 Ainsworth BE, Haskell WL, Leon AS, et al. Compendium of physical activities: classification of energy costs of human physical activities. Med Sci Sports Exerc 1993;25:71-80.

30 McMurdo ME. Physical activity and health in old age. Scott Med J 1997;42:154-5.

31 Carlson JE, Ostir GV, Black SA, et al. Disability in older adults. 2: Physical activity as prevention. Behav Med 1999;24:157-68.

32 Barton H, Tsourou C. Healthy urban planning. London: Spon Press, 2000.

33 Tokyo Citizens Council for Health Promotion. Towards Health Town Initiatives: case studies. Tokyo: Tokyo Metropolitan Public Health Promotion Foundation, 1999

34 Dunn JR, Hayes MV. Social inequality, population health and housing: a study of two Vancouver neighborhoods. Soc Sci Med 2000;51:563-87.

35 Davey Smith G, Neaton JD, Wentworth D, et al. Socioecoomic differential in mortality risk among men screened for the multiple risk factor intervention trial: I white men. Am J Public Health 1996:86:486-96.

36 Wolfson M, Rowe G, Gentlemen JF, et al. Career earnings and death: a longitudinal analysis of older Canadian men. J Gerontol 1993;48:S167-79. 